\title{
El nuevo Reglamento de Hechos de Importancia en el Perú
}

\author{
Lilian Rocca Carbajal ${ }^{1}$
}

\section{Consideraciones iniciales}

Como parte del proceso de reforma del mercado de valores, se vienen emitiendo, desde fines de 2011, una serie de dispositivos legales y reglamentarios que tienen por finalidad establecer un marco normativo orientado a promover el mercado de valores, principalmente a través del acceso de un mayor número de emisores; promover mecanismos orientados a elevar la liquidez de los valores que se negocian, como por ejemplo haber introducido el mecanismo de acceso directo al mercado (DMA o ADM) y el agente promotor de liquidez; facilidades y simplificación en los diferentes trámites de inscripción de valores, tanto en ofertas públicas primarias como en los listados en la bolsa de valores, como la creación de una ventanilla única para la inscripción de valores de oferta pública

1 Las reflexiones académicas desarrolladas en el presente artículo parten del ejercicio docente de la autora como profesora del curso Derecho del Mercado de Valores, en la Facultad de Derecho de la Universidad de Lima. Desde este ámbito, se destaca la importancia de la transparencia como uno de los principales fundamentos de la regulación del mercado de valores, a propósito del reciente Reglamento de Hechos de Importancia e Información Reservada, así como las características de sus principales disposiciones. 
secundaria, o el uso de formularios electrónicos estructurados denominados e-prospectus, para la inscripción de ofertas públicas primarias de valores, que es una experiencia única en el mundo que ha generado buenos comentarios y que posiblemente pronto será imitada; ampliación del mercado local a través del reconocimiento para la oferta pública de valores inscritos por las autoridades de mercados de valores altamente desarrollados (Estados Unidos de América, Canadá, Reino Unido y demás países de referencia ${ }^{2}$ ), o de la región, como los países que conforman el Mercado Integrado Latinoamericano (MILA) y la Alianza del Pacífico; profesionalización del mercado de valores; inclusión financiera a través de la creación del mercado alternativo de valores (MAV) para hacer viable el ingreso al mercado de valores de pequeñas y medianas empresas; la creación de un segmento para las denominadas ofertas híbri$d a s^{3}$, que comprende la oferta de valores mobiliarios que se dirigen a inversionistas institucionales; el uso cada vez más intensivo de tecnología de la información (TI) para la conexión con los administrados de la SMV, ya sea a través del sistema MVNet o SMV Virtual; las mejoras propuestas en el segmento de mineras júniors; y otras reformas y cambios que se harán de conocimiento público más adelante.

De este modo, la autoridad del mercado de valores peruano se ha enfocado, en los últimos años, en lo que constituye su razón de ser o deberes fundamentales: velar por la protección de los inversionistas, la eficiencia y transparencia de los mercados bajo su supervisión, la correcta formación de precios y la difusión de toda la información necesaria para tales propósitos, a través de la regulación, supervisión y promoción ${ }^{4}$.

2 Por ejemplo, en el Reglamento de Inscripción y Exclusión de Valores Mobiliarios en el Registro Público del Mercado de Valores y en la Rueda de Bolsa, aprobado por Resolución SMV n. ${ }^{\circ}$ 031-2012-SMV/01, se reconoce la posibilidad de que se puedan inscribir valores de los denominados países de referencia, como Alemania, Francia, España, Noruega, Holanda, Suiza, Rusia, Italia, India, China, Japón, Australia, Brasil, entre otros.

3 Son aquellas ofertas de valores que por estar dirigidas a inversionistas institucionales presentan características propias de las ofertas privadas, pero el prospecto informativo respectivo se registra o deposita en el regulador, tal como ocurre con las ofertas públicas.

4 De acuerdo con el artículo 1 del texto único concordado de la Ley Orgánica de la SMV, aprobado por Decreto Ley n. ${ }^{\circ} 26126$, "La Superintendencia del Mercado de Valores (SMV) es un organismo técnico especializado adscrito al 
$\mathrm{Al}$ respecto, es preciso señalar que la International Organization of Securities Commissions (IOSCO en inglés; OICV, por sus siglas en castellano), organización que reúne a los diversos supervisores de los mercados de valores a nivel mundial, señala que los tres objetivos de la regulación de los mercados de valores son: (i) la protección de los inversores; (ii) garantizar que los mercados sean justos, eficientes y transparentes; y (iii) la reducción del riesgo sistémico.

Respecto al segundo principio, y en específico sobre la transparencia del mercado de valores, IOSCO (2003) señala que "En un mercado eficiente, la difusión y publicación de información relevante es puntual y generalizada, lo cual se refleja en el proceso de formación de los precios. La regulación deberá promover la eficiencia del mercado".

En cuanto al objetivo y principio de transparencia de los mercados de valores, se aprecia que la legislación internacional los desarrolla fundamentalmente sobre la base de dos aspectos: (i) la transparencia de la información de los emisores de valores, y (ii) la transparencia sobre la información de la negociación de los valores. Ambos aspectos se han desarrollado en los artículos 10, 11 y 12 de la Ley del Mercado de Valores, Decreto Legislativo n. ${ }^{\circ} 861$ (LMV).

Para cautelar la transparencia de la información de los emisores, que es el tema que nos ocupa en el presente documento, se aprecia que la regulación la aborda esencialmente a través del deber de información de los emisores de valores que participan en los mercados públicos y organizados. Es aquí donde nace la necesidad de exigir a los emisores que comuniquen (divulguen) sus hechos de importancia (en adelante, $\mathrm{HI}$ ) o información esencial, material o relevante, que son algunas de las denominaciones que se utilizan en otras jurisdicciones.

Sobre el deber de información de los emisores, Alfonso Pérez Carballo (2005) señala: "Ha de exigirse que, como mínimo, las sociedades transmitan al mercado la información sobre cuáles adoptan y cuál es su

\footnotetext{
Ministerio de Economía y Finanzas, que tiene por finalidad velar por la protección de los inversionistas, la eficiencia y transparencia de los mercados bajo su supervisión, la correcta formación de precios y la difusión de toda la información necesaria para tales propósitos, a través de la regulación, supervisión y promoción. Tiene personería jurídica de derecho público interno y goza de autonomía funcional, administrativa, económica, técnica y presupuestal, constituyendo un pliego presupuestario $[\ldots]^{\prime \prime}$.
} 
grado de observancia en cada caso, para que los inversores puedan formarse un juicio correcto sobre esas sociedades". Dicho autor señala también: "En los mercados financieros, la información es la piedra angular sobre la que descansa todo el sistema para que los precios se formen adecuadamente y se pueda tutelar la posición de quienes en ellos actúan" (2005). Y además nos dice:

La información se transmite de forma simétrica, equitativa y en tiempo útil. Finalmente, la información ha de ser transmitida al mercado en forma equitativa y simétrica: todos los partícipes del mercado deben tener acceso a una información sustancialmente igual en un mismo horizonte temporal, por lo que las sociedades deben trasladar a los accionistas e inversores, en general, el contenido de las presentaciones facilitadas a bancos de inversión, analistas, agencias de calificación, accionistas significativos y a todos los depositarios de información sensible a partir del momento en que esta información sea conocida por la sociedad. El momento en que se transmite la información al mercado tiene también la mayor relevancia. De nada sirve una información correcta, equitativa y simétrica si no se transmite en el momento en que esa información es conocida por la propia sociedad (2005, pp. 682, 684 y 685).

Bajo el marco de las consideraciones expuestas, la SMV emitió el nuevo Reglamento de Hechos de Importancia e Información Reservada, aprobado por Resolución SMV n. ${ }^{\circ}$ 005-2014-SMV/01, publicado en el diario oficial El Peruano el 20 de marzo de 2014 (en adelante, el Reglamento), con vigencia desde el 1 de julio de 2014.

El Reglamento incorpora una serie de novedades, tales como: (1) una definición de HI basada en la capacidad de ejercer influencia significativa en los inversionistas o en el mercado; (2) inmediatez en la comunicación, pues los $\mathrm{HI}$ deben ser comunicados tan pronto como ocurran o se tome conocimiento de los mismos, y en ningún caso más allá del día que alguna de esas dos situaciones se produzca; (3) sistematización, y reducción a 34, de los supuestos que conforman la lista de información que por su naturaleza puede calificar como HI; (4) desarrollo del deber de diligencia de los emisores; (5) desarrollo de reglas sobre el contenido, formas, medios y procedimientos de difusión de los HI; (6) precisiones aplicables a la información reservada; (7) política informativa y contenido de las normas internas de conducta, con precisión de los procedimientos y protocolos internos que debe aplicar cada emisor para la 
gestión de su información relevante; (8) profesionalización del representante bursátil y reforzamiento de su función como vocero oficial del emisor; (9) precisiones respecto de los $\mathrm{HI}$ de las sociedades administradoras de fondos y de los patrimonios autónomos que administran; (10) herramientas para el seguimiento, difusión y supervisión a cargo de la Bolsa de Valores, entre otras. A continuación, se desarrollan los principales temas que contiene el Reglamento.

\section{Marco legal de los hechos de importancia (HI)}

El artículo 28 de la LMV establece el marco legal a partir del cual se desarrolla la definición, alcance, sujetos obligados, oportunidad, obligaciones y demás aspectos relacionados con la comunicación de los $\mathrm{HI}$ en el mercado de valores ${ }^{5}$.

Del análisis de dicha disposición se aprecia que ésta establece lineamientos fundamentales respecto a:

- Importancia: Como criterio esencial de la definición de los HI, el cual debe medirse en función de la influencia que pueda ejercer la información sobre un inversionista sensato para modificar su decisión de invertir o no en el valor.

- Obligados: Estarán obligados a comunicar HI quienes inscriban en el Registro Público del Mercado de Valores (RPMV) un valor o programa de emisión. Se incluye la comunicación de negociaciones en curso, respecto del obligado, su valor o la oferta que de éste se haga.

- Atributos: Los HI deben cumplir con los requisitos de veracidad, suficiencia y oportunidad, mencionados también en el artículo 10 de la LMV.

- Destino: Si bien se señala que los HI deben ser comunicados a la SMV y, de ser el caso, a la Bolsa en que se encuentre inscrito el valor del obligado, la finalidad es que en estas instituciones se

5 Nótese que el Título II de la Ley del Mercado de Valores, denominado “Transparencia del mercado", contiene de manera sistemática las disposiciones referidas a la revelación, difusión o comunicación de información esencial que es necesaria para la formación de precios de los valores materia de oferta pública y para la adopción de decisiones de inversión respecto de dichos valores. 
centralicen los $\mathrm{HI}$, y que luego ellas, por su función, a través de sus respectivos medios de difusión, divulguen la información, con lo cual se implementan los medios formales de difusión de HI.

- Oportunidad: Los HI deben ser reportados a las instituciones mencionadas y divulgados tan pronto como el hecho ocurra o el obligado tome conocimiento del mismo, según sea el caso.

Este marco legal principal de referencia de los $\mathrm{HI}$ se complementa en el artículo 34 de la LMV. Así, en esta disposición se establece la posibilidad, bajo ciertas formalidades o requisitos, de asignar a un hecho o negociación en curso, el carácter de reservado, cuando su comunicación prematura o en la oportunidad prevista por el artículo 28 de la LMV pueda acarrear perjuicio al emisor. De este modo, la calificación de un HI como reservado, cumplidos los requisitos y condiciones para ello, hace posible que se postergue la obligación de comunicar los $\mathrm{HI}$ tan pronto como ocurran o se conozcan.

Como puede verse, si bien la LMV contiene el marco normativo fundamental de los HI, existe una serie de aspectos que necesitan precisarse, desarrollarse y ampliarse, lo que precisamente se hace en el Reglamento.

\section{Definición y calificación de los hechos de importancia}

Establecer una definición adecuada o integral sobre lo que constituye un HI ha sido, es y seguirá siendo uno de los retos más difíciles de resolver para los distintos reguladores de los mercados de valores del mundo. Ello se explica en gran parte por la dinámica, desarrollo y evolución del propio mercado, que hace que una definición de $\mathrm{HI}$ con características fijas, circunscriba su alcance y se desfase rápidamente, poniendo en riesgo el fin perseguido de preservar la transparencia del mercado.

La legislación comparada sobre la materia nos indica que las diferentes definiciones de $\mathrm{HI}$ se han diseñado partiendo de lineamientos o características generales, hasta concretarse en definiciones, criterios e inclusive listados enunciativos de supuestos de HI. Como elementos comunes en tales definiciones se aprecian textos expresados en un sentido de posibilidad o de potencialidad, que fundamentalmente se refieren a dos aspectos: (i) el efecto en la cotización o precio del valor, y (ii) el efecto en las decisiones de inversión (en adelante, componentes).

Así, alrededor de estos dos componentes, con más o menos palabras, o con un desarrollo más o menos complejo, se construyen casi todas las 
definiciones de $\mathrm{HI}$ que se aplican en la legislación comparada internacional. En ese contexto, el Reglamento de HI contiene en su definición los dos componentes mencionados. El Reglamento define un HI como cualquier acto, decisión, acuerdo, hecho, negociación en curso o información referida al emisor, a los valores de éste o a sus negocios, que tengan la capacidad de influir significativamente en: (1) la decisión de un inversionista sensato para comprar, vender o conservar un valor; o (2) la liquidez, el precio o la cotización de los valores emitidos. La definición de HI también comprende la información del grupo económico del emisor que éste conozca o que razonablemente debía conocer, siempre que dicha información tenga capacidad de influir significativamente en el propio emisor o en sus valores.

\subsection{Capacidad de influencia significativa}

La evaluación sobre la capacidad de provocar un efecto importante en el precio de un valor o en la decisión de un inversionista, es una tarea que corresponde al emisor u obligado. El carácter ex ante de dicha evaluación hace que esa tarea pueda parecer compleja; sin embargo, la regulación parte del hecho concreto de que es el emisor el que posee la información y, por tanto, está en una posición que le permite determinar si la misma es capaz de tener el efecto sustancial en alguno de los dos componentes mencionados (precio o decisión).

De este modo, en el Reglamento se establece que el emisor, para evaluar la capacidad de influencia significativa de la información y su posible calificación como HI, debe considerar la trascendencia o magnitud del acto, acuerdo, hecho, negociación en curso, decisión o conjunto de circunstancias en su actividad, patrimonio, resultados, situación financiera o posición empresarial o comercial en general; o en sus valores o en la oferta de éstos; así como en el precio o la negociación de sus valores.

\subsection{El estándar del "inversionista sensato"}

Como se ha mencionado, el artículo 3 del Reglamento define a un HI como cualquier acto, decisión, acuerdo, hecho, negociación en curso o información referida al emisor, a los valores de éste o a sus negocios, que tengan la capacidad de influir significativamente en la decisión de un inversionista sensato para comprar, vender o conservar un valor, o en la liquidez, el precio o la cotización de los valores emitidos. 
En el supuesto de la definición, se observa la inclusión del estándar o paradigma del inversionista sensato, el cual también se encuentra previsto en el segundo párrafo del artículo 28 de la LMV, debiéndose entender que este es el paradigma de inversionista cuya protección es finalidad de la citada ley. De conformidad con el Diccionario de la lengua española (DRAE) "sensato" significa "prudente, cuerdo, de buen juicio". Es decir, el legislador ha establecido que el tipo de inversionista objeto de protección por la normativa del mercado de valores, es aquel que actúa de manera prudente, cuerda y con buen juicio. Sin embargo, una adecuada comprensión del estándar requiere ir más allá del aspecto semántico, puesto que es necesario determinar qué elementos lo configuran, $y$, para este propósito, juegan un rol crucial los distintos pronunciamientos -tanto administrativos como de sede judicial y constitucional- y la doctrina.

Precisamente, en el marco normativo y reglamentario del mercado de valores cabe destacar que el entonces Tribunal Administrativo de la Conasev se pronunció con respecto al estándar o paradigma del inversionista sensato, mediante Resolución n. ${ }^{\circ}$ 032-2002-EF/94.12 del 18 de junio de 2002, señalando que es aquel que...

Se caracteriza en general, por no ser demasiado astuto ni demasiado torpe, no es un profesional en la materia, aunque cuenta con suficiente capacidad para entender el sentido de sus actos, tiene un cierto conocimiento y/o experiencia sobre el comportamiento del mercado y de las normas que lo regulan, es suficientemente consciente del riesgo que éste implica, medita antes de tomar una decisión de inversión adoptando precauciones razonables y dedica un tiempo prudencial a la obtención de información y, en general, al manejo de sus inversiones.

Este criterio fue ratificado igualmente mediante Resolución n. ${ }^{0} 116-$ 2003-EF/94.12 del 28 de octubre de 2003, cuando dicho Tribunal Administrativo se pronunció con respecto al estándar del inversionista sensato, señalando que se trata del...

[...] hombre razonable y se caracteriza en general por no ser demasiado astuto ni demasiado torpe, ni extremadamente diligente ni absolutamente negligente. No es un profesional en la materia, aun-

6 En su vigesimosegunda edición. 
que cuenta con suficiente capacidad para entender el sentido de sus actos, tiene un cierto conocimiento y/o experiencia sobre el comportamiento del mercado y es suficientemente consciente del riesgo que éste implica, dedicando un tiempo prudencial a la obtención de información y, en general, al manejo de sus inversiones.

Considerando el pronunciamiento del Tribunal Administrativo del 2003 -que, así lo entendemos, supera y enriquece al de 2002-, se puede colegir que, bajo ese enfoque, un inversionista sensato sería alguien que cuenta con determinadas cualidades tanto a nivel personal como en su condición de inversionista.

A nivel personal estas cualidades son la razonabilidad, la conciencia de sus actos, la de poseer un grado medio de habilidad y la de contar con un nivel de diligencia promedio. En su condición de inversionista, dichas cualidades consisten en que, aun cuando no es un profesional en la materia, cuenta con conocimientos y experiencia sobre el mercado, posee un nivel adecuado de conciencia sobre el riesgo que este implica $\mathrm{y}$, prudentemente, dedica tiempo para obtener información del mercado y manejar sus inversiones.

\section{Listado de hechos de importancia}

En el artículo 17 del anterior reglamento se establecía que los actos, hechos, acuerdos o decisiones enunciados en la lista incluida en el primer anexo del mismo debían considerarse como HI, debiendo el emisor informarlos bajo esa calificación, precisándose que ello debía hacerse siempre que tales situaciones generen una o más de las consecuencias establecidas en el artículo 4 de tal reglamento.

Esta técnica de incluir listas enunciativas de hechos, actos, acuerdos $\mathrm{u}$ otras situaciones que pueden considerarse como HI, es utilizada en casi la mayoría de legislaciones de mercados de valores altamente desarrollados. La principal diferencia que se aprecia sobre dichas listas, es que en algunos países la lista de posibles HI es taxativa, es decir, únicamente se consideran $\mathrm{HI}$ las situaciones enunciadas en la lista.

En otros países, la lista de potenciales HI es enunciativa o referencial, $\mathrm{y}$ en algunos casos, como en nuestro anterior reglamento de $\mathrm{HI}$, se requiere, para la calificación como $\mathrm{HI}$, de la presencia de las condiciones que definen a un HI en cada legislación, es decir, a los dos componentes antes mencionados o alguno de ellos. 
Bajo tales premisas, el artículo 5 del Reglamento -titulado "información que por su naturaleza puede calificar como hecho de importancia" - señala que la norma incluye una lista enunciativa de hechos, actos, acuerdos y decisiones, que tiene como propósito facilitar al emisor la identificación, determinación y clasificación de la información que podría calificar como un HI.

Asimismo, la referida disposición señala que los supuestos contenidos en dicha lista deben comunicarse como HI cuando tengan capacidad de "influencia significativa", según la propia definición de un HI. Asimismo, se indica que si algún acto, decisión, acuerdo, hecho o negociación en curso no figura en dicha lista, no significa necesariamente que no califique como HI. De igual modo, se precisa que cualquier HI definido como tal en alguna norma especial debe seguir comunicándose bajo esa condición.

Finalmente, con relación a la calificación de los HI por parte del emisor, se establece que éste en todo momento debe actuar diligentemente para comunicar sus HI, y que en caso de tener alguna duda sobre si determinada información califica como tal, debe optar por revelarla como HI.

Con relación al listado de HI, es necesario reiterar que el Reglamento contiene 34 supuestos definidos que podrían calificar como HI, en lugar de los más de 200 tipos que incluyó el anterior reglamento, muchos de los cuales presentaban el inconveniente de que sus textos eran o muy abiertos o poco precisos.

Contar con una lista más corta y con 34 supuestos mejor definidos, representa una innovación y facilidad para los emisores, en la medida en que es más sencillo para ellos -ante un hecho o acto a evaluar-identificar primero si este se encuentra contenido o no en la lista, y luego determinar si tiene la capacidad de generar los dos componentes de la definición de un HI. Cabe agregar que de la comparación de las dos listas (la vigente y la del anterior reglamento), se aprecia que existen nuevos supuestos que pueden calificar como HI y otros, que son los más, que se han dejado de lado.

\section{Oportunidad para comunicar HI}

El artículo 28 de la LMV establece que el hecho de importancia debe ser divulgado tan pronto como ocurra o el emisor tome conocimiento del 
mismo, según sea el caso. En esa línea, el numeral 9.1 del artículo 9 del Reglamento dispone que el emisor debe informar el $\mathrm{HI}$ tan pronto como este ocurra o tome conocimiento del mismo, y en ningún caso más allá del día en que este haya ocurrido o haya sido conocido.

Dicho plazo de comunicación es distinto al del anterior reglamento de la materia, el cual establecía como plazo máximo de presentación hasta el día siguiente hábil de ocurrido el hecho o de haber tomado conocimiento del mismo. Este cambio ha sido uno de los que más discusión ha merecido por parte del público en el marco del proceso de consulta ciudadana seguido previamente a la aprobación del Reglamento, en el sentido de que se debía mantener el plazo del anterior reglamento, puesto que un ajuste al mismo, según las diversas objeciones planteadas al cambio, generaría inconvenientes a los emisores. Sin embargo, tal como se advierte de la simple lectura del citado artículo de la LMV, el plazo establecido en el nuevo Reglamento -y no en el anterior- es el más consistente con lo establecido en el artículo 28 de la LMV.

Es necesario anotar aquí, a manera de historia, que en la oportunidad en la que entró en vigencia el anterior reglamento (año 2002), la remisión de información debía realizarse por medios físicos y debía entregarse en dos ventanillas distintas: la de Conasev (hoy, Superintendencia del Mercado de Valores) y la de la Bolsa de Valores de Lima. En dicha época, esa era la manera de remitir la información por parte de los emisores (información financiera, memoria anual, hechos de importancia y otros).

Esta situación cambió de manera significativa en el 2003, con la implementación del sistema MVNet y con la creación de la ventanilla única para la comunicación de HI. Con ello, la remisión de información por parte de los emisores dejó de hacerse de manera física para realizarse por vía electrónica, y ya no se remitía la información dos veces sino solo una, puesto que mediante el uso de la tecnología de información se hizo posible que la información fuera remitida, mediante un solo acto, a la SMV y a la Bolsa de Valores de Lima, y difundida de manera simultánea en los portales de ambas instituciones. Y desde esa oportunidad a la fecha, los mecanismos de envío de información se vienen optimizando permanentemente para facilitar el envío de información por parte de los emisores.

Entonces, es un hecho que la forma y mecanismos para la presentación o comunicación de información existente en la fecha de entrada en vigencia del anterior reglamento (2002) y los actuales (sistema MVNet y ventanilla única) son radicalmente diferentes. Y es por esta razón prin- 
cipalmente -es decir, la desaparición de los límites existentes por la remisión de información de manera física, como son la distancia y las dos ventanillas de entrega- que no resultaba razonable mantener el plazo del anterior reglamento.

Es preciso indicar que el Reglamento contiene dos situaciones de excepción respecto al plazo de comunicación de HI. La primera es cuando el hecho ocurre o se toma conocimiento del mismo en un día no hábil, supuesto en el cual el emisor debe comunicarlo a más tardar el día hábil siguiente y antes del inicio de la sesión de negociación del mecanismo centralizado de negociación en el que se encuentre listado su valor. La otra es la referida a los supuestos de información reservada, en los cuales el emisor podrá, bajo su propia responsabilidad, asignar a un hecho o negociación en curso el carácter de información reservada, y con ello retrasar su difusión, cuando determine que su divulgación prematura puede causarle un perjuicio.

De otro lado, como elemento adicional respecto a la oportunidad en la remisión de información que califica como $\mathrm{HI}$, es necesario señalar que esta debe ser comunicada a la SMV antes que a cualquier otra persona, entidad o medio de difusión, y simultáneamente cuando corresponda a la Bolsa o a la entidad administradora del mecanismo centralizado de negociación respectivo. Es decir, no basta comunicarla tan pronto como el hecho ocurra o se tome conocimiento de él, sino que el emisor debe tomar todas las previsiones y los recaudos necesarios para que la primera entidad en ser informada sea la SMV, y con ello el mercado.

Lo que esta precisión de la norma pretende evitar es que se produzca alguna situación de asimetría informativa entre los inversionistas, así como el potencial uso de información privilegiada por parte de alguno de ellos. El medio para ello es que todos los inversionistas, simultáneamente, conozcan la misma información de un emisor, y ello se logra mediante la difusión de los HI a través del portal de la SMV y de la BVL.

Por tanto, aun cuando un emisor cumpla con remitir su información de manera pronta $u$ observando los plazos límites establecidos en el Reglamento para determinados supuestos, el hecho es que si una persona, entidad o medio de difusión conoce dicha información antes que la $\mathrm{SMV}$, el emisor puede incurrir en infracción a la normativa del mercado de valores y podría ser sancionado en consecuencia.

Finalmente, es necesario señalar que, con respecto a la oportunidad en la que un hecho ocurre, el Reglamento ha establecido una presunción 
en el sentido de que el emisor conoce de un HI referido a él cuando dicho hecho se origina en su propia organización o accionista de control; cuando es comunicado o informado de la ocurrencia del hecho o es un hecho que se ha divulgado o difundido públicamente. En adición, se considera que un emisor tiene conocimiento de un $\mathrm{HI}$ referido a él que se origina en la entidad controladora de su grupo económico, cuando existen indicios razonables de que sus principales funcionarios han tomado conocimiento del hecho, o si razonablemente el emisor pudo conocerlo.

\section{Medios, formas de comunicación y difusión}

Con relación a los medios a través de los cuales se deben informar los $\mathrm{HI}$, es pertinente recordar que, de acuerdo con la normativa aplicable a los participantes del mercado de valores, y cuya obligación es consignada de manera expresa en el Reglamento, los emisores de valores deben comunicar sus HI utilizando la ventanilla única electrónica del sistema MVNet ${ }^{7}$.

Es necesario mencionar que conforme lo establecen los numerales 7.2 y 7.3 del artículo 7 del Reglamento, los hechos de importancia deben ser remitidos de acuerdo con las especificaciones técnicas que aprueba para dicho efecto la SMV, en cuyo caso solo se dará por cumplida la obligación si se han observado dichas especificaciones.

En cumplimiento de dicha disposición normativa, con fecha 01 de julio de 2014, a través de la Resolución de Superintendencia n. ${ }^{\circ} 080-$ 2014-SMV/02 se han aprobado, con el fin de establecer las especificaciones para el envío de información a la SMV de parte de sus supervisados, las "Especificaciones Técnicas del Sistema de Informa-

7 De conformidad con el artículo 11 del Reglamento del sistema MVNet y SMV Virtual, aprobado por Resolución de Superintendencia n. ${ }^{\circ}$ 010-2013-SMV/01, “El MVNet es un sistema WEB de intercambio de información, que permite el almacenamiento de información, utiliza la firma digital, autenticación y canales para el intercambio de información seguro y eficiente, entre las entidades obligadas y la SMV".

Asimismo, de conformidad con lo establecido en el artículo 23 del reglamento antes citado: "El MVNet constituye una ventanilla única para el envío de información conjunta a la SMV y a las Bolsas por parte de las entidades obligadas", y "La información se entenderá remitida a ambas instituciones a la vez, mediante el envío de la referida información vía MVNet". 
ción de Registro y Supervisión - SIRYS", documento que se encuentra en el portal del Mercado de Valores.

\section{Deber de diligencia}

El Reglamento ha asignado determinadas obligaciones a los emisores de valores responsables de la revelación de HI. En ese sentido, dicha norma llena de contenido el deber de diligencia que compete a cada emisor cuando tenga que calificar y remitir HI. Dicha conceptualización reviste importancia, ya que ese concepto tiende a abarcar obligaciones de manera indeterminada; sin embargo, el Reglamento, de manera acertada, ha determinado las obligaciones que el emisor debe cumplir, con la finalidad de observar el cumplimiento de su deber de diligencia.

De esta forma se cuenta con un concepto propio y aplicable a los emisores que califiquen y revelen la información calificada como HI. Dicho concepto resulta independiente de los demás conceptos que las normas puedan atribuir a los emisores y en las que se han especificado obligaciones, dependiendo del rol que el emisor se encuentre desarrollando. Así, tenemos que en cuanto compete a los emisores, estos cuentan con diversas obligaciones, dependiendo del rol que asuman en determinado momento. De esta manera, por ejemplo, es distinto el deber de diligencia que deberá observar un emisor que coloque valores por oferta pública primaria, que la del emisor que a través del órgano competente convoque a junta de accionistas, o la del emisor que acuerde y proceda a repartir dividendos en mandato de lo establecido por sus estatutos y las leyes pertinentes.

En ese sentido, el artículo 6 del Reglamento ha consignado aquellas actividades que el emisor debe realizar a fin de cumplir con su deber de diligencia en su rol de informante de HI. Los emisores cumplirán con su deber de diligencia cuando se aseguren que la información que califiquen y comuniquen tenga la capacidad de influir significativamente, de acuerdo con la definición establecida en los artículos 3 y 4 del Reglamento; cuando actúen con imparcialidad en la comunicación de los HI e información reservada; cuando vigilen el cumplimiento de los mecanismos de control establecidos en sus normas internas de conducta; cuando aclaren o desmientan, o, en su caso, comuniquen como HI después de haber tomado conocimiento, la información publicada en medios de comunicación; y cuando comuniquen como HI aquella información que cumpla con lo establecido en los artículos 3 y 4 del Reglamento. 
Como puede deducirse, el cumplimiento del deber de diligencia implica establecer mecanismos y controles internos que permitan responder de manera adecuada y oportuna a las circunstancias que se presenten. Como parte de dicha implementación, el Reglamento señala que el emisor debe adoptar una política informativa y establecer normas internas de conducta.

Dichas materias han sido abordadas por el Reglamento. Específicamente, el artículo 18 del Reglamento ha consignado diversas obligaciones con relación a la política informativa que el emisor está obligado a establecer. Por su parte, el artículo 19 del Reglamento ha detallado el concepto y las obligaciones correspondientes a las normas internas de conducta de competencia de los emisores participantes del mercado de valores.

\section{Política informativa}

Esta impone obligaciones para el propio emisor, sus directivos, sus funcionarios y las demás personas que se encuentren vinculadas al emisor, las cuales tienen por finalidad que la oportunidad en la revelación de los HI se cumpla de acuerdo con lo establecido en el Reglamento.

Se establece la obligación de asegurar la simultaneidad de la revelación de la información, prohibiendo en ese sentido que la información se difunda por medios de comunicación, inclusive Internet, correo electrónico y redes sociales o a periodistas. Asimismo, se prohíbe que dicha información sea revelada o difundida en reuniones con inversores o accionistas, analistas de inversiones o similares, al margen que tengan o no una participación significativa en el capital de la entidad, siendo la excepción que dicha información les sea revelada, en su caso, por razón de su cargo de administradores.

\section{Normas internas de conducta}

En cuanto a las normas internas de conducta, estas tienen por finalidad establecer disposiciones internas de obligatorio cumplimiento; en ese sentido, constituyen verdaderas instrucciones que son de obligatorio cumplimiento. Dichas disposiciones deberán desarrollar y observar todas las obligaciones comprendidas en el Reglamento, es decir, entre otras, deberán establecer mecanismos, procedimientos e instancias que deben seguirse para salvaguardar la confidencialidad de la información reservada, determinando los procedimientos internos para la califica- 
ción, elaboración y la comunicación de los hechos de importancia a la SMV y a la Bolsa de Valores. De este modo, las normas internas de conducta han de contribuir a que la información que el emisor proporcione y comunique como HI e información reservada, sea veraz, clara, suficiente y oportuna.

El Reglamento, de manera acertada, ha previsto el concepto de las normas, el órgano responsable y contenido de las mismas. De esta manera, el artículo 19 del Reglamento aborda el concepto de normas internas de conducta, el órgano responsable y el contenido de las mismas.

Cabe resaltar que de acuerdo con lo dispuesto por el numeral 1.17 del anexo I, del Reglamento de Sanciones, aprobado por Resolución Conasev n. ${ }^{\circ}$ 055-2001-EF/94.10, constituye infracción de naturaleza muy grave "No contar o no implementar o infringir las normas internas de conducta del emisor con respecto a la información que suministra a la SMV", lo que implica que quien no observe lo establecido en las mencionadas normas podrá ser materia de una sanción de multa mayor de cincuenta (50) UIT y hasta setecientas (700) UIT, circunstancia que refuerza la obligatoriedad del cumplimiento de las mencionadas normas.

\section{Representante bursátil (RB)}

La responsabilidad de comunicar HI corresponde al emisor, quien además debe cumplir con todos los requisitos y condiciones establecidos para tal fin. No obstante ello, al igual que en el anterior reglamento, la norma vigente establece que el emisor debe designar a una persona natural para que se encargue de efectuar dichas comunicaciones. A esta persona se la denomina representante bursátil, y además de comunicar $\mathrm{HI}$, tiene por función responder oportuna y efectivamente todas las consultas o requerimientos de información vinculados con la difusión de HI e información reservada que formule la SMV o la Bolsa de Valores.

Asimismo, el Reglamento le asigna otras funciones al RB, como la remisión a la SMV de toda la información periódica o eventual a que se encuentra obligado el emisor por las normas que le son aplicables. En ese sentido, el RB se encargará de enviar los estados financieros del emisor, la información sobre su grupo económico, la información relacionada con la supervisión o seguimiento de las ofertas públicas primarias del emisor, la información vinculada a la entrega de beneficios, entre otro tipo de información. 
El Reglamento exige que el emisor cuente al menos con un RB titular y con un suplente. No se fija un máximo de RB titulares o suplentes, en cambio se deja en libertad al emisor para que determine la cantidad de RB que tendrá, indicándose que el emisor será responsable de los actos que sus RB ejecuten en el desarrollo de sus funciones.

\subsection{Profesionalización del RB y sus requisitos}

Respecto a los requerimientos de profesionalización que se viene exigiendo a las personas naturales que actúan en nombre de los distintos partícipes del mercado de valores, en el Reglamento se establece que los RB deben contar con título profesional o grado académico de educación superior y además con capacitación en materias relacionadas con el mercado de valores. Cubrir esta necesidad resulta coherente con el hecho de que en la mayoría de los casos, los RB podrían ser quienes tengan que efectuar la evaluación para determinar si un acto, hecho o situación califica como HI, y, por consiguiente, deban comunicarlo oportunamente; y en ese sentido se requiere que el RB sea una persona que cuente con el nivel profesional establecido y con experiencia para desempeñar sus funciones de manera adecuada y diligente.

Además, el Reglamento exige como condiciones y requisitos para que una persona pueda ejercer la función de RB, que sea designada por el directorio del emisor y que cuente con facultad para atender y responder en nombre del emisor, y con celeridad, las consultas o requerimientos que le formule la SMV o la Bolsa de Valores, sobre los aspectos que contiene el Reglamento.

\subsection{RB suplente}

El Reglamento también prevé que en caso de fallecimiento, renuncia, remoción, enfermedad, ausencia o imposibilidad de ejercer el cargo por parte del RB titular, otro titular o el suplente designado lo reemplazarán de manera inmediata. En este caso se asume que la comunicación de hechos de importancia realizada por el RB suplente se ha realizado por ausencia del titular. Es preciso indicar que se exige que el RB suplente cumpla con los requisitos y condiciones que se demanda al RB titular. 


\section{Negociación en curso e información reservada}

Una negociación en curso puede calificar como hecho de importancia siempre que tenga capacidad de influencia significativa en los términos del artículo 3 del Reglamento.

Ahora bien, según el artículo 9, numeral 9.3 del Reglamento, un emisor podrá, bajo su propia responsabilidad, asignar a un hecho o negociación en curso el carácter de información reservada a que se refiere la LMV e informarla como tal a la SMV, y con ello retrasar su difusión, cuando determine que la divulgación prematura de la misma puede causarle un perjuicio.

Lo anterior supone, por un lado, que un emisor debe informar una negociación en curso como hecho de importancia, salvo que dicha divulgación pudiera causarle un perjuicio, supuesto en el cual igual debe informar a la SMV, pero bajo el procedimiento previsto para la información reservada, y, por otro lado, ello también supone que un emisor no puede limitarse a comunicar los resultados de una negociación sin haber previamente informado (como hecho de importancia o de manera reservada) la existencia de la negociación que le dio origen.

De acuerdo con la experiencia, y respecto a la observancia de esta obligación, los emisores manifiestan que el tema que mayor dificultad presenta es la determinación del momento preciso a partir del cual el emisor se encuentra obligado a comunicar la negociación en curso como hecho de importancia o de manera reservada. El hecho es que, en efecto, siendo tan diversos los procesos de negociación y las formas de negociar, resulta sumamente difícil identificar un acto o momento a partir del cual se establezca que el emisor se encuentra incurso ya en un proceso de negociación y, por ende, obligado a informar.

Precisamente, frente a esa situación, el Reglamento no precisa o determina un acto o momento a partir del cual un emisor se encuentra obligado a informar sobre la existencia de una negociación en curso, dejando en libertad a los emisores para que sean ellos los que determinen el momento en el que, en virtud de los avances, propuestas, compromisos, acuerdos verbales o escritos y la existencia de otras formalidades del proceso de negociación, puedan determinar de manera razonable que se encuentran en el marco de una negociación que deben informar.

Habiendo determinado que el emisor se encuentra inmerso en una negociación en curso, éste debe proceder a informar dicha situación como 
hecho de importancia o calificar dicha información como reservada para retrasar su difusión. Si optara por la segunda alternativa, el emisor debe proceder a informar a la SMV, observando lo establecido en el artículo 13 del Reglamento, es decir, remitiendo una comunicación a la SMV adjuntando copia del acta de directorio -o de su parte pertinente- debidamente certificada. Esta información califica como información privilegiada.

Dicha comunicación, según el artículo 13, numeral 13.2 del Reglamento, debe contener una explicación detallada sobre el hecho o negociación en curso, declaración de que el hecho o negociación en curso ha sido materia de un acuerdo de reserva adoptado con el voto favorable de por lo menos las tres cuartas partes de los miembros del directorio $\mathrm{u}$ órgano social equivalente, fundamentación de la adopción del acuerdo de reserva, precisando por qué la divulgación prematura puede generarle perjuicio, indicación del plazo durante el cual se mantendrá la reserva de la información y una declaración del emisor en el sentido de que es responsable de asegurar y garantizar la reserva y confidencialidad de la información señalando las medidas adoptadas para tal efecto. Asimismo, adjuntará la relación completa de las personas que conocen la información, una declaración de haber cumplido con exigir un compromiso de confidencialidad a las personas que conozcan la información y una declaración de obligarse a informar permanentemente cualquier acto significativo relacionado con la información materia de su comunicación durante la fase de reserva.

La copia del acta o de su parte pertinente, según el artículo 13, numeral 13.3, del Reglamento, debe contener la identificación de los miembros del directorio y de los que votaron a favor del acuerdo -que deben representar por lo menos las tres cuartas partes de dicho órgano-, una explicación detallada sobre el hecho o negociación en curso, fundamentación de la adopción del acuerdo de asignación de reserva precisando por qué la divulgación prematura del hecho o negociación en curso puede generarle perjuicio, y el acuerdo adoptado con indicación del plazo expresamente determinado, durante el cual el hecho o negociación en curso mantendrá el carácter de reservado, y la decisión de comunicar dicho acuerdo a la SMV.

Luego, la SMV verifica si la comunicación y documentos que presente el emisor cumplen con la normativa, o si debe realizar subsanaciones. Verificado el cumplimiento de los requisitos establecidos, el superintendente del Mercado de Valores da conformidad al plazo de reserva indicado por el emisor, o puede ajustarlo a su solo criterio. Si los requisitos 
no estuvieren completos, el emisor debe subsanarlos y, de no hacerlo, debe proceder a la difusión inmediata de la información, y si no lo hace, la SMV dispone, de manera irrecurrible, su difusión.

Antes del vencimiento del plazo de reserva concedido por la SMV, el emisor puede solicitar de manera sustentada la necesidad de su extensión adjuntando copia del acta o de su parte pertinente, en la que conste el acuerdo del directorio de solicitar la extensión del plazo de reserva.

El cese de la calificación de información reservada se produce por cualquiera de los siguientes supuestos: (i) desaparición de las causas o razones que motivaron la reserva; (ii) vencimiento del plazo de reserva que cuenta con la conformidad de la SMV; (iii) decisión del emisor de hacer pública la información materia de la reserva. Una vez que cese el carácter reservado de la información, esta debe ser informada por el emisor al mercado como hecho de importancia, salvo que se trate de una negociación en curso en la que no se haya concretado acuerdo alguno.

La existencia de noticias en los medios de comunicación, que tengan relación con el contenido fundamental del hecho reservado, o la presencia de movimientos atípicos en el precio o volumen del valor durante el plazo de reserva, constituyen indicios razonables de que la información reservada se ha difundido de manera prematura, parcial o distorsionada, y que su confidencialidad y reserva no han sido aseguradas o garantizadas debidamente por el emisor. En este supuesto, la SMV podrá requerir al emisor para que proceda a la difusión de la información como hecho de importancia. Dicho requerimiento es irrecurrible, y ante su incumplimiento, la SMV procederá a su difusión.

\section{Los HI y los nuevos principios de gobierno corporativo en el Perú}

En el ámbito internacional, en los últimos años, se ha venido enfatizando el rol de la transparencia de la información en el ámbito de la protección de los inversionistas. Esto ha quedado evidenciado sobre todo ante las distintas crisis corporativas que ocurrieron, como Enron (2001), WorldCom (2002) y Parmalat (2003), y, más recientemente, durante la última crisis financiera internacional, y en medio de ella la quiebra de Lehman Brothers (2010) -uno de los bancos de inversión norteamericanos más importantes- por problemas en el mercado de las denominadas hipotecas subprime en los Estados Unidos. Todos estos casos estuvieron vinculados a aspectos de transparencia de la información. 
IOSCO resalta precisamente la importancia de prácticas como la divulgación completa, precisa y oportuna de los resultados financieros, riesgos y toda información relevante para las decisiones de los inversionistas, así como el uso de normas de contabilidad de alta calidad en la preparación de estados financieros, incluyéndolos entre los principios que deberían regir a los mercados de valores.

En esta línea destaca la importancia que reviste el cumplimiento de prácticas de buen gobierno corporativo para promover una mayor transparencia de la información, pues estas alinean los intereses de accionistas, gerentes y directores, reforzando así la confianza de los inversionistas y otros grupos de interés vinculados con las empresas, aspecto que constituye además uno de los ejes fundamentales de la nueva regulación asociada con la revelación de HI.

Los inversionistas consideran cada vez más la aplicación de prácticas de buen gobierno como un elemento de suma importancia para preservar el valor real de sus inversiones en el largo plazo, en la medida que conlleva a eliminar la información desigual entre quienes administran la empresa y sus inversionistas, adquiriendo especial relevancia que dicha información sea confiable, veraz y oportuna. Refuerza este objetivo la existencia de un adecuado marco legal y de prácticas de supervisión eficientes que velen por la existencia de mercados transparentes que garanticen la protección del inversionista, aspecto sobre el cual la SMV ha puesto especial énfasis en el marco de su ámbito de acción.

El cumplimiento de dichas prácticas por parte de las empresas trae consigo una mejor administración del riesgo; generan valor, solidez y eficiencia en las empresas emisoras; promueven un clima de respeto a los derechos de los accionistas y de los inversionistas en general; facilitan el acceso al mercado de capitales y la reducción del costo de capital, entre otras ventajas.

Reconociendo ello, en noviembre de 2013, como resultado del esfuerzo conjunto de catorce instituciones públicas y privadas lideradas por la SMV, se publicó el Código de Buen Gobierno Corporativo para las Sociedades Peruanas. Este documento presenta una estructura acorde con las necesidades y características propias del mercado de valores peruano, y en particular de las empresas peruanas, poniendo especial énfasis no solo en la dinámica de la junta general de accionistas (propiedad), el directorio (administración y gobierno) y la alta gerencia (gestión ordinaria), sino también en el sistema integral de gestión de riesgos y de control interno. 
El nuevo Código reconoce que su adopción es voluntaria. Sin embargo precisa que la sociedad que los asuma debe ser capaz de demostrar su adhesión documentadamente, mediante los mecanismos o documentos societarios, tales como estatutos, reglamentos, políticas o normativas internas que mantenga vigentes, así como su efectiva aplicación en línea con el principio internacionalmente reconocido "cumple o explica".

En esta orientación, el marco normativo existente se complementa con una serie de principios considerados a nivel internacional como buenas prácticas, que las sociedades que cuenten con valores inscritos en el RPMV deberán revelar al mercado, en línea con el principio de transparencia en la información, su grado de adhesión a dichos principios, con el fin de que los inversionistas puedan incorporar dicha información en sus decisiones de inversión.

En línea con la transparencia de la información, y por tanto con el Reglamento, en el Código destacan aspectos de especial relevancia, como que toda sociedad debe contar con una política de información para los accionistas, inversionistas, demás grupos de interés y el mercado en general, con lo cual define de manera formal, ordenada e integral los lineamientos, estándares y criterios que se aplicarán en el manejo, recopilación, elaboración, clasificación, organización y distribución de la información que genera o recibe la sociedad. La política de información abarca toda aquella que pudiera influir en las decisiones económicas de sus grupos de interés, tales como los objetivos de la sociedad, la lista de los miembros del directorio y de la alta gerencia, la estructura accionaria, la descripción del grupo económico al que pertenece y los estados financieros, entre otros.

Asimismo, el Código destaca el hecho de que los accionistas tienen derecho a recibir y requerir información oportuna, confiable y veraz, que les permita velar adecuadamente por sus derechos, incluyendo mecanismos de acceso permanente para expresar su opinión sobre el desarrollo de la sociedad, características que a su vez destacan en el Reglamento, al exigirse que la información sea revelada al mercado con la inmediatez debida, que permita a los inversionistas tomar sus decisiones de inversión.

Del mismo modo, se destaca como principio que las sociedades deben determinar los responsables y medios por los cuales oportunamente informa y absuelve los requerimientos de información de los accionistas, tales como páginas web corporativas, oficina de relación con inversionistas y reuniones informativas. Al respecto, el Reglamento también destaca el rol de la página web corporativa como un medio 
para que las empresas revelen sus HI, lo que se encuentra alineado con la relevancia que los principios dan a este medio de difusión de información, reconocido incluso en otras legislaciones como una exigencia de cumplimiento obligatorio.

Al respecto, es importante resaltar que desde la perspectiva del gobierno corporativo, el enfoque debe ser que "La información vaya a los accionistas y no que los accionistas tengan que ir a la información".

Finalmente, consideramos que el Reglamento dota al mercado de un marco normativo acorde con sus necesidades, evolución y complejidad, representando una mejora significativa en el estándar de transparencia, y contribuye a elevar la protección de los inversionistas. En su elaboración, se ha considerado la experiencia en la materia recogida en los últimos años, los principios sobre regulación emitidos por IOSCO, los principios de buen gobierno corporativo, las sugerencias de los grupos de interés involucrados tras haberse sometido el proyecto de norma a consulta ciudadana, y la legislación de los países con mercados de valores altamente desarrollados, buscando también armonización con la legislación de los países del MILA y de la Alianza del Pacífico.

\section{Referencias}

Beneyto, J.M. \& Martínez-Echevarría, A. (2005). El espacio financiero único en la Unión Europea-Los mercados de valores. España: Ediciones Jurídicas y Sociales.

Castilla, M. (2001). Regulación y competencia en los mercados de valores. España: Civitas Ediciones.

International Organization of Securities Commissions. (mayo, 2003). Objectives and Principles Of Securities Regulation. 2014 de Oisco sitio web: http://www.iosco.org/library/pubdocs/pdf/IOSCOPD154.pdf

Pérez Carballo, Alfonso. (2005). La protección de los inversores y la transparencia. En Beneyto, J.M., \& Martínez-Echevarría, A. El espacio financiero único en la Unión Europea-Los mercados de valores. España: Ediciones Jurídicas y Sociales.

Serrano, J. (2007). Mercados financieros. Colombia: Ediciones Uniandes.

Superintendencia de Mercado de Valores. (noviembre, 2003). Código de Buen Gobierno Corporativo para las Sociedades Peruanas 2013. 2014 Sitio web: http://www.smv.gob.pe/ConsultasP8/temp/GobCorporativo2013.pdf 
Varios. (2010). Estudio sobre la transparencia de los emisores en Iberoamérica. España: Fundación Instituto Iberoamericano de Mercados de Valores (IIMV).

Varios. (2011). Compendio de mercado de valores. Lima: Editora y Distribuidora Ediciones Legales "Ius Et Veritas".

\section{Legislaciones}

Alemania - Wertpapierhandelsgesetz - WPHG (Ley del Mercado de Valores).

Australia - Corporations Act (Ley de Corporaciones) - 2001.

Chile - Ley n. ${ }^{\circ} 18.045$ - Ley del Mercado de Valores.

Chile - Norma de Carácter General n. ${ }^{\circ} 30$ de la Superintendencia de Valores y Seguros (SVS) de Chile.

Chile - Circular n. ${ }^{\circ} 988$ de la Superintendencia de Valores y Seguros de Chile.

Colombia - Decreto 2555 del 15 de julio de 2010 o decreto único por el cual se recogen y reexpiden las normas en materia del sector financiero, asegurador y del mercado de valores, y se dictan otras disposiciones.

Ecuador - Ley de Mercado de Valores.

Ecuador - Resolución CNV n. ${ }^{\circ}$ 008-2006 de la Comisión Nacional de Valores de Ecuador.

España - Ley 24/1998 - Ley del Mercado de Valores del Reino de España.

España - Circular EHA/1421/2009 de la Comisión Nacional del Mercado de Valores.

Estados Unidos - Securities and Exchange Act 1934 (Ley de Valores y Bolsas).

Estados Unidos - Form 8-K de la Securities and Exchange Comission.

México - Ley de Mercado de Valores del 30 de diciembre de 2005.

México - Disposiciones de carácter general aplicables a las emisoras de valores y a otros participantes del mercado, de la Comisión Nacional Bancaria y de Valores, publicadas el 19 de marzo de 2003.

Reino Unido - DTR Handbook.

Unión Europea - Directiva 2003/06/CE del Parlamento Europeo. 